\title{
Marijuana Use Among 10th Grade Students — Washington, 2014
}

\author{
Anar Shah, $\mathrm{MPH}^{1}$; Mandy Stahre, $\mathrm{PhD}^{2}$
}

Some studies have suggested that long-term, regular use of marijuana starting in adolescence might impair brain development and lower intelligence quotient $(1,2)$. Since 2012, purchase of recreational or retail marijuana has become legal for persons aged $\geq 21$ years in the District of Columbia, Alaska, California, Colorado, Maine, Massachusetts, Nevada, Oregon, and Washington, raising concern about increased marijuana access by youths. The law taxing and regulating recreational or retail marijuana was approved by Washington voters in 2012 and the first retail licenses were issued in July 2014; medical marijuana use has been legal since 1998 . To examine the prevalence, characteristics, and behaviors of current marijuana users among 10th grade students, the Washington State Department of Health analyzed data from the state's 2014 Healthy Youth Survey (HYS) regarding current marijuana use. In 2014, 18.1\% of 10th grade students (usually aged 15-16 years) reported using marijuana during the preceding 30 days; of these students, $32 \%$ reported using it on $\geq 10$ days. Among the marijuana users, $65 \%$ reported obtaining marijuana through their peer networks, which included friends, older siblings, or at a party. Identification of comprehensive and sustainable public health interventions are needed to prevent and reduce youth marijuana use. Establishment of state and jurisdiction surveillance of youth marijuana use could be useful to anticipate and monitor the effects of legalization and track trends in use before states consider legalizing recreational or retail marijuana.

HYS is a cross-sectional, self-administered, pencil-and-paper survey that has been administered to Washington students in 6th, 8th, 10th, and 12th grades in public schools during the fall of even-numbered years since 2002. HYS uses a clustered sampling design in which public schools with at least 15 students in each grade are randomly selected and all students in eligible grades at participating schools are invited to complete the survey. The sample is representative of Washington public school students (3). To assess marijuana use prevalence, analysis was limited to students in 10th grade because of the gradespecific sampling nature of HYS and a sufficient sample size and response rate to allow for robust analysis (3).

Students were asked how many days during the past 30 days they had used marijuana. Current marijuana use was defined as use of marijuana on $\geq 1$ day during the preceding 30 days. Percentages were calculated and bivariate analyses were performed to compare the prevalence of marijuana use by sex, race, Hispanic ethnicity, language spoken at home, and academic achievement. Prevalence of preceding 30-day marijuana use was estimated with $95 \%$ confidence intervals, and statistical significance was assessed using independent samples t-test comparison for sex, race, and Hispanic ethnicity, language spoken in home, and academic achievement. Bonferroni correction was used to restrict Type I error at 5\% for race/ethnicity. To assess

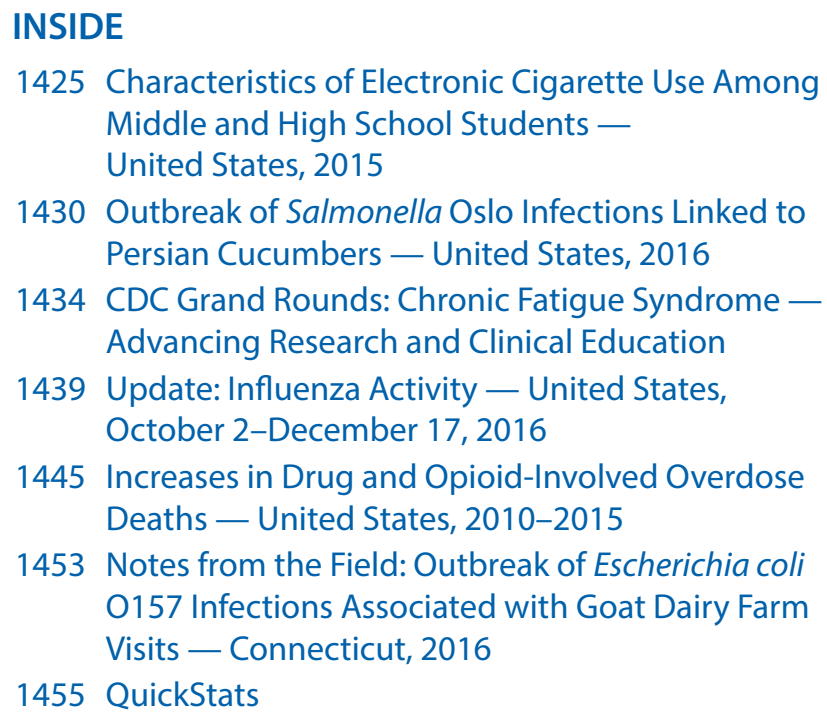

1425 Characteristics of Electronic Cigarette Use Among Middle and High School Students United States, 2015

1430 Outbreak of Salmonella Oslo Infections Linked to Persian Cucumbers - United States, 2016

1434 CDC Grand Rounds: Chronic Fatigue Syndrome Advancing Research and Clinical Education

1439 Update: Influenza Activity - United States, October 2-December 17, 2016

1445 Increases in Drug and Opioid-Involved Overdose Deaths - United States, 2010-2015

1453 Notes from the Field: Outbreak of Escherichia coli 0157 Infections Associated with Goat Dairy Farm Visits - Connecticut, 2016

1455 QuickStats

Continuing Education examination available at http://www.cdc.gov/mmwr/cme/conted_info.html\#weekly.

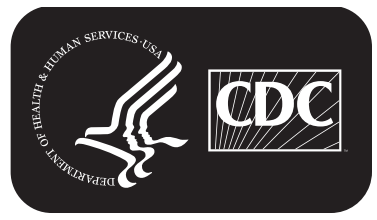

U.S. Department of Health and Human Services Centers for Disease Control and Prevention 
trends over time during 2002-2014, joinpoint regression* with a maximum number of joinpoints of " 1 " was used. To analyze use of various other substances, students were asked about past 30-day cigarette, e-cigarette, and alcohol use, and past 2-week binge drinking (defined for both males and females as consuming five or more drinks in a row).

Respondents also were asked how they obtained their marijuana with the following response options: "I did not get marijuana in the past 30 days," "I bought it from a store," "I got it from friends," "I got it from a party," "I got it from an older brother or sister," "I gave money to someone to get it for me," "I took it from home without my parents' permission," and "I got it from home with my parents' permission." Responses were combined for reporting peer network (i.e., friends, party, or sibling).

In 2014, a total of 192 schools (response rate $=87 \%$ ) and 8,821 10th grade students (response rate $=66 \%$ ) provided data for the analyses (3). Among the 8,821 students, 8,579 answered the marijuana question, $1,556(18.1 \%)$ reported past 30-day marijuana use (Table 1 ) and that percentage did not change significantly during 2002-2014 ( $\mathrm{p}=0.214$ ) (3). In 2014, past 30 -day use prevalence was higher among 10th grade students who identified as non-Hispanic American Indian/Alaska Native (33.5\%), non-Hispanic black (26.4\%), and Hispanic (23.4\%) than among students who identified as non-Hispanic white (17.2\%) and non-Hispanic Asian (7.7\%). There was no
TABLE 1. Number of 10th grade students surveyed and percentage who reported using marijuana on $\geq 1$ of the preceding 30 days, by selected characteristics - Healthy Youth Survey, Washington, 2014

\begin{tabular}{lrcr}
\hline Characteristic & $\begin{array}{c}\text { No. in } \\
\text { sample* }(\%)\end{array}$ & $\begin{array}{c}\text { No. who reported } \\
\text { marijuana use }\end{array}$ & $\begin{array}{c}\text { Crude prevalence } \\
(95 \% \mathrm{Cl})\end{array}$ \\
\hline Overall & $\mathbf{8 , 8 2 1 ( 1 0 0 )}$ & $\mathbf{1 , 5 5 6}$ & $18.1(16.6-19.8)$ \\
Sex & & & \\
Male & $4,263(48.4)$ & 782 & $19.0(17.1-21.0)$ \\
Female & $4,542(51.6)$ & 767 & $17.3(15.6-19.1)$ \\
Race/Ethnicity & & & \\
White, non-Hispanic & $4,919(56.0)$ & 829 & $17.2(15.3-19.3)$ \\
Black, non-Hispanic & $430(4.9)$ & 108 & $26.4(22.2-31.1)$ \\
Al/AN, non-Hispanic & $211(2.4)$ & 68 & $33.5(27.2-40.4)$ \\
Asian, non-Hispanic & $819(9.3)$ & 62 & $7.7(6.0-9.7)$ \\
Pacific Islander, & $191(2.2)$ & 33 & $17.7(13.1-23.6)$ \\
$\quad$ non-Hispanic & & & \\
Hispanic & $1,255(14.3)$ & 280 & $23.4(21.0-25.9)$ \\
Other non-Hispanic & $489(5.6)$ & 84 & $17.9(15.0-21.3)$ \\
$\begin{array}{l}\text { Multiracial non-Hispanic } \\
\text { Language usually spoken at home }\end{array}$ & $468(5.3)$ & 90 & $19.8(16.3-23.7)$ \\
$\begin{array}{l}\text { Non-English/All other } \\
\text { English }\end{array}$ & $1,545(18.0)$ & 252 & $17.0(14.7-19.5)$ \\
$\begin{array}{l}\text { School performance } \\
\text { Mostly A and B grades }\end{array}$ & $6,2053(82.0)$ & 1256 & $18.2(16.5-20.1)$ \\
Mostly C, D, or F grades & $2,230(26.4)$ & 699 & $13.1(11.6-14.7)$ \\
\hline
\end{tabular}

Abbreviations: $\mathrm{Al} / \mathrm{AN}=$ American Indian/Alaska Native; $\mathrm{Cl}=$ confidence interval. * A total of 242 responses were missing from the 8,821 10th grade students, reducing the denominator for overall marijuana use to 8,579 . Denominators for the other categories might be $<8,579$ because some participants only responded to the overall marijuana use question.

\footnotetext{
${ }^{*}$ https://surveillance.cancer.gov/joinpoint/index.html.
}

The MMWR series of publications is published by the Center for Surveillance, Epidemiology, and Laboratory Services, Centers for Disease Control and Prevention (CDC), U.S. Department of Health and Human Services, Atlanta, GA 30329-4027.

Suggested citation: [Author names; first three, then et al., if more than six.] [Report title]. MMWR Morb Mortal Wkly Rep 2016;65:[inclusive page numbers]

\section{Centers for Disease Control and Prevention}

Thomas R. Frieden, MD, MPH, Director

Harold W. Jaffe, MD, MA, Associate Director for Science

Joanne Cono, MD, ScM, Director, Office of Science Quality

Chesley L. Richards, MD, MPH, Deputy Director for Public Health Scientific Services

Michael F. Iademarco, MD, MPH, Director, Center for Surveillance, Epidemiology, and Laboratory Services

\section{MMWR Editorial and Production Staff (Weekly)}

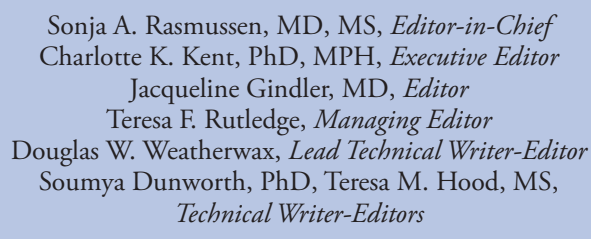

Timothy F. Jones, MD, Chairman

Matthew L. Boulton, MD, MPH Virginia A. Caine, MD

Katherine Lyon Daniel, PhD

Jonathan E. Fielding, MD, MPH, MBA

David W. Fleming, MD

Martha F. Boyd, Lead Visual Information Specialist Maureen A. Leahy, Julia C. Martinroe, Stephen R. Spriggs, Moua Yang, Tong Yang, Visual Information Specialists

Quang M. Doan, MBA, Phyllis H. King, Terraye M. Starr, Information Technology Specialists

MMWR Editorial Board

William E. Halperin, MD, DrPH, MPH

King K. Holmes, MD, PhD

Robin Ikeda, MD, MPH

Rima F. Khabbaz, MD

Phyllis Meadows, PhD, MSN, RN

Jewel Mullen, MD, MPH, MPA
Jeff Niederdeppe, $\mathrm{PhD}$

Patricia Quinlisk, MD, MPH

Patrick L. Remington, MD, MPH Carlos Roig, MS, MA

William L. Roper, MD, MPH

William Schaffner, MD 
difference in prevalence of marijuana use by sex or by language spoken at home. Prevalence of past 30-day marijuana use was higher among 10th graders who had poor school performance (32.3\%) compared with students who reported mostly getting A or B grades (13.1\%) (Table 1).

Approximately $37 \%$ of current 10 th grade marijuana users reported using marijuana for 1-2 days during the preceding 30 days, and $32 \%$ reported using it for $\geq 10$ days. More females than males reported marijuana use for $1-2$ days ( $40.4 \%$ versus $33.6 \%)$ or $3-5$ days $(24.1 \%$ versus $15.5 \%)$, whereas more males than females reported marijuana use for $\geq 10$ days during the past month (38.4\% versus $26.2 \%$ ).

The most commonly reported means of obtaining marijuana among 10th grade marijuana users was from peers (65\%) or by giving someone money to purchase it $(18 \%)$. Six percent of students reported purchasing marijuana from a store themselves, and $11 \%$ reported getting it from home with or without their parents' permission.

Greater percentages of marijuana users than nonmarijuana users reported smoking (combustible tobacco) cigarettes (30.6\% versus $2.8 \%)$, drinking alcohol (64.3\% versus $10.9 \%)$, and using e-cigarettes (61.7\% versus $8.3 \%)$ during the preceding 30 days, and binge drinking during the preceding 2 weeks (38.3\% versus $4.3 \%)$ (Table 2 ).

\section{Discussion}

Nationally, marijuana use among 10th grade students has been estimated at $15 \%$ to $24 \%(4,5)$. In $2014,18.1 \%$ of Washington 10th grade students used marijuana at least once during the preceding 30 days, and this prevalence has been fairly consistent since 2002 (3). After Washington legalized recreational marijuana for persons aged $\geq 21$ years in 2012, recreational or retail stores had opened by the summer of 2014; medical marijuana has been legal in the state since 1998.

Among Washington 10th grade students who reported using marijuana, about one third reported using it frequently (i.e., on $\geq 10$ days in the past 30 days). School performance appears to be associated with marijuana use, as has been supported by previous studies (G); however, it cannot be determined from this study design if those with worse grades in school are just more likely to use marijuana or if marijuana is contributing to poor school performance. Most youths who are using marijuana are getting it from their peers, a finding that is similar for other substances ( 7$)$. Moreover, $11 \%$ of students are getting marijuana from their own home. Educating adults and parents about the potential harms of marijuana use might be one potential strategy to help prevent youth marijuana initiation.

Approximately twice as many marijuana users reported using e-cigarettes $(61.7 \%)$ than combustible cigarettes (30.6\%). Some electronic cigarette devices can be used for either nicotine or marijuana, and reports have shown a recent increase in e-cigarette use (8). Tenth-grade marijuana users in Washington reported a higher prevalence of other substance use than nonmarijuana users. The use of more than one substance among marijuana users is concerning because all of the other substances in the survey have detrimental effects, and the interactive effects on youths are not well understood (9).

The findings in this report are subject to at least five limitations. First, data were collected only from youths attending public schools in Washington and might not be representative of all 10th grade students, although they are representative of the $93 \%$ of students who attend public schools. Second, data are self-reported and thus possibly subject to underreporting or overreporting of use of marijuana or other substances, including recall or response bias. Third, these estimates might differ from other nationally representative youth surveillance systems, in part because of differences in survey methods, survey type and topic, age and setting of target population, and time of year the survey was conducted. Fourth, HYS uses a five-drink cut-point for both males and females to define youth binge-drinking, which might result in underreporting of this behavior, because a four-drink limit is the standard for females. ${ }^{\dagger}$ Finally, medical marijuana was legalized in Washington in 1998 , and the effects on marijuana prevalence among youths are not known because of a lack of historical (baseline) data before this legalization.

$\bar{\dagger}$ https://www.cdc.gov/alcohol/fact-sheets/binge-drinking.htm.

TABLE 2. Prevalence of use of various other substances by 10th grade marijuana users compared with nonmarijuana users - Healthy Youth Survey, Washington 2014

\begin{tabular}{|c|c|c|c|c|c|}
\hline Substance & $\begin{array}{l}\text { No. }(\%) \text { of } \\
\text { respondents }\end{array}$ & $\begin{array}{c}\text { No. of } \\
\text { marijuana users }\end{array}$ & $\begin{array}{c}\text { Crude prevalence of other } \\
\text { substance use among } \\
\text { marijuana users, } \\
\%(95 \% \mathrm{Cl})\end{array}$ & $\begin{array}{c}\text { No. of } \\
\text { nonmarijuana users }\end{array}$ & $\begin{array}{c}\text { Crude prevalence of other } \\
\text { substance use among } \\
\text { nonmarijuana users, } \\
\%(95 \% \mathrm{Cl})\end{array}$ \\
\hline Tobacco cigarettes & $684(7.9)$ & 473 & $30.6(26.9-34.5)$ & 196 & $2.8(2.3-3.4)$ \\
\hline Alcohol & $1,772(20.6)$ & 996 & $64.3(61.3-67.1)$ & 765 & $10.9(10.0-11.8)$ \\
\hline Binge drinking* & 904 (10.6) & 593 & $38.3(35.6-41.1)$ & 303 & $4.3(3.7-5.1)$ \\
\hline E-cigarettes & $798(17.8)$ & 496 & $61.7(56.6-66.5)$ & 301 & $8.3(7.0-9.8)$ \\
\hline
\end{tabular}

Abbreviation: $\mathrm{Cl}=$ confidence interval.

* Consumed five or more alcoholic drinks in a row during the preceding 2 weeks. 


\section{Summary}

What is already known about this topic?

Marijuana use among adolescents and young adults can impair brain development, lower intelligence quotient, and adversely affect development, including lower academic retention, social interaction and emotional development and other mental health effects. National surveys have been tracking marijuana use among youths. A number of states, including Washington, have legalized purchase of marijuana for recreational use among persons aged $\geq 21$ years.

What is added by this report?

Approximately $18 \%$ of 10 th grade students in Washington reported using marijuana at least 1 day during the preceding 30 days, and almost one third of these students used marijuana $\geq 10$ days during the preceding 30 days. Prevalence of use differed by race and ethnicity and school performance and was highest among American Indian/Alaska Native students. The most common means of obtaining marijuana among the 10th graders was from their peers, and youths who use marijuana also were more likely to report alcohol and e-cigarette use than youths who do not use marijuana. Although recreational marijuana use was legalized in Washington in 2012 for persons aged $\geq 21$ years, the prevalence of marijuana use among 10th graders did not change during 2002-2014.

What are the implications for public health practice?

Although national level estimates for marijuana use exist, statelevel marijuana use along with detailed information on youth access is needed for states to develop effective intervention and prevention strategies aimed at youth marijuana use. As more states legalize medical and recreational marijuana, surveillance needs to be established to monitor trends in use by youths.

Regular marijuana use in adolescence is associated with impaired school performance and an increased risk for early school dropout (6). Preventing youth marijuana initiation and use can avoid harms associated with marijuana (10). As more states move to legalize marijuana for medical use or retail purchase, concerns about new and broader access to marijuana by youths are increasing. Although several successful strategies and recommendations are offered in the Community Preventive Services Task Force's Community Guide to reduce youth alcohol and tobacco use, ${ }^{\S}$ marijuana use is not a category in the Community Guide, which limits identifying and supporting implementation of strategies that are federally endorsed to reduce this behavior or prevent harms associated with marijuana use.

\footnotetext{
\$ https://www.thecommunityguide.org/.
}

Interventions and policies focused on reducing tobacco and alcohol use might be adapted for reducing marijuana use in states that have legalized sales, including limiting advertising and retailer density, enforcing minimum purchasing age, prohibiting public use of marijuana indoors and outdoors, conducting screening and brief interventions in medical settings, and increasing marijuana taxes and other price controls. Data on medical marijuana sales and diversion might also provide information regarding youth access. More research is needed to identify which programs and prevention strategies are most effective in reducing youth use and initiation of marijuana.

\section{Acknowledgments}

Trevor Christensen, Chronic Disease Assessment Unit, Washington State Department of Health.

\footnotetext{
${ }^{1}$ Maternal and Child Health Assessment Unit, Washington State Department of Health; ${ }^{2}$ Forecasting and Research Division, Washington State Office of Financial Management.
}

Corresponding author: Anar Shah, anar.shah@doh.wa.gov, 360-236-3748.

\section{References}

1. Zalesky A, Solowij N, Yücel M, et al. Effect of long-term cannabis use on axonal fibre connectivity. Brain 2012;135:2245-55. http://dx.doi. org/10.1093/brain/aws136

2. Meier MH, Caspi A, Ambler A, et al. Persistent cannabis users show neuropsychological decline from childhood to midlife. Proc Natl Acad Sci US A 2012;109:E2657-64. http://dx.doi.org/10.1073/pnas.1206820109

3. Washington State Department of Social and Health Services, Department of Health, Office of the Superintendent of Public Instruction, and Liquor and Cannabis Board. Healthy Youth Survey 2014 analytic report. Olympia, WA; 2016. http://www.askhys.net/Docs/HYS\%202014\%20 Analytic\%20Report\%20FINAL\%204-5-2016.pdf

4. Kann L, Kinchen S, Shanklin SL, et al. Youth risk behavior surveillanceUnited States, 2013. MMWR Suppl 2014;63(No. SS-4):1-168. https:// www.cdc.gov/mmwr/pdf/ss/ss6304.pdf.

5. Johnston LD, O’Malley PM, Miech RA, Bachman JG, Schulenberg JE. Monitoring the future national survey results on drug use: 1975-2014: overview, key findings on adolescent drug use. Ann Arbor, MI: Institute for Social Research, University of Michigan; 2015. http://www. monitoringthefuture.org/pubs/monographs/mtf-overview2014.pdf

6. Volkow ND, Baler RD, Compton WM, Weiss SR. Adverse health effects of marijuana use. N Engl J Med 2014;370:2219-27. http://dx.doi. org/10.1056/NEJMra1402309

7. Harrison PA, Fulkerson JA, Park E. The relative importance of social versus commercial sources in youth access to tobacco, alcohol, and other drugs. Prev Med 2000;31:39-48. http://dx.doi.org/10.1006/pmed.2000.0691

8. Arrazola RA, Singh T, Corey CG, et al. Tobacco use among middle and high school students-United States, 2011-2014. MMWR Morb Mortal Wkly Rep 2015;64:381-5.

9. Raphael B, Wooding S, Stevens G, Connor J. Comorbidity: cannabis and complexity. J Psychiatr Pract 2005;11:161-76. http://dx.doi. org/10.1097/00131746-200505000-00004

10. American Psychological Association. Regular marijuana use bad for teens' brains, study finds. Rockville, MD: ScienceDaily; 2014. https://www. sciencedaily.com/releases/2014/08/140809141436.htm 